
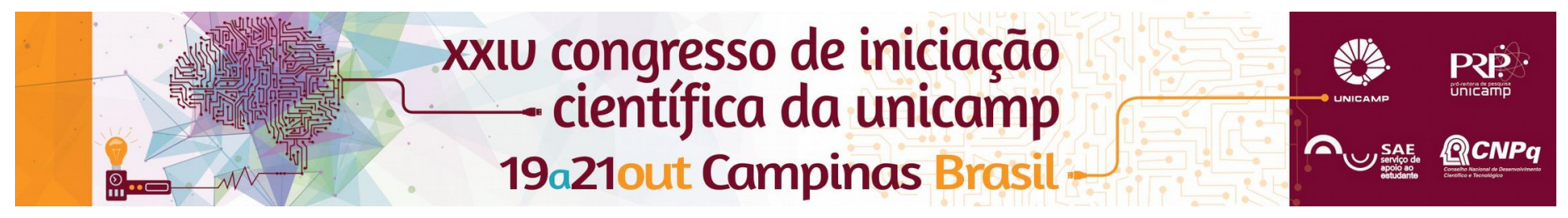

\title{
Localização de centros de saúde para o atendimento de epidemias: 0 caso dengue.
}

\author{
Aline N. Arakaki*, Ana Paula Milanez, Anibal T. Azevedo.
}

\section{Resumo}

O projeto consiste no estudo dos problemas de healthcare utilizando a área de pesquisa operacional para dar suporte à tomada de decisões. Busca-se estudar os modelos matemáticos de localização de facilidades healthcare na literatura e adequá-los ao caso da epidemia da dengue na cidade de São Paulo. Além disso, serão analisados cenários e suas respectivas performances da proposta de atendimento a ser realizada pela rede de centros de saúde.

\section{Palavras-chave:}

Problema de localização, Health Care, Otimização Combinatória

\section{Introdução}

Os problemas de healthcare estão associados a prevenção, tratamento e cuidado de doenças ligadas à saúde mental e bem-estar físico. A localização das facilidades (centro de saúde) têm sido amplamente aplicados em projetos de atendimento emergencial e de prevenção de doenças.

Os problemas de localização de facilidades healthcare tendem a considerar três pontos: acessibilidade, adaptabilidade, e eficácia. A acessibilidade considera o quão fácil é para o paciente ser atendido em uma facilidade. A adaptabilidade realiza o planejamento considerando situações futuras e a possibilidade de responder a uma nova demanda. E por fim, a eficácia considera se há como prestar serviço aos pacientes e quantos pacientes podem ser atendidos.

Além disso, os pesquisadores de localização de facilidades públicas destinadas à prevenção de doenças em Quebec no Canadá, Veter e Lapierre (2002), assumem que a distância é o maior determinante da participação da população nos programas de prevenção.

Considerando todos os fatores relevantes, foi utilizado como base os modelos matematicos: de localização por cobertura de Toregas, ReVelle e Berrman (1971), e o de localização por cobertura máxima com capacidade proposto por Radiah Sharriff, Moin e Omar (2012).

Devido a falta de dados em relação ao número de leitos nos hospitais e pronto-socorro, os modelos citados acima foram readaptados.

Para encontrar as soluções ótimas dos modelos matemáticos do escopo do projeto foi utilizado o solver GLPK (GNU Linear Programming Kit) que resolve problemas de programação linear de grande porte e programação inteira mista, atendendo a proposta do projeto.

\section{Resultados e Discussão}

Com o intuito de formular um modelo matemático mais adequado a São Paulo, a cidade foi fragmentada em regiões e separada por distritos. Além disso, foi determinado a utilização de apenas prontossocorros e hospitais municipais, pois parte da população não possui acesso aos centros particulares.

Devido a indisponibilidade da informação do número de leitos dos hospitais o modelo criado apresenta a capacidade dos hospitais como uma variável de decisão, um valor não pré-definido.

Os modelos são projetados para minimizar a distância que as pessoas percorrem no trajeto até o hospitais e prontos-socorros. A tabela 1 fornece o valor da função objetivo empregada para avaliação da qualidade das soluções em cada cenário.

Tabela 1. Minimização da distância percorrida pelos pacientes na região Norte da cidade de São Paulo (km).

\begin{tabular}{|l|l|l|l|l|}
\hline Cenário & 1 & 2 & 3 & 4 \\
\hline Distância & 91,9 & 97,76 & 125,8 & 119 \\
\hline
\end{tabular}

Assim, foram considerados 4 cenários:

1) Todos os hospitais e prontos-socorros podem ter a capacidade máxima (considerada a demanda de todas as pessoas com dengue);

2)Os hospitais e prontos-socorros tem capacidade igualmente distribuida;

3)Apenas hospitais operando;

4)Apenas prontos-socorros operando;

Através da análise dos resultados, é possível constatar que os prontos socorros estão melhores localizados comparado aos hospitais para o menor deslocamento dos pacientes vítima da epidemia de Dengue. Além disso, obteve-se os locais ótimos para localização de centros de saúde, capacidade dos mesmos e a população designada para ser atendida em cada centro.

\section{Conclusão}

Através do estudo dos problemas de localização de facilidades healthcare foi possível formular um modelo matemático que atendesse os pacientes da cidade de São Paulo minimizando a distância que os mesmos percorrem e analisando os locais ótimos

\section{Agradecimentos}

Gostaria de agradecer meus familiares e amigos, além disso aqueles que fizeram parte para o desenvolvimento desse projeto, meu orientador Anibal Azevedo, a co-orientadora Ana Paula Milanez e o doutorando Leonardo Takahashi.

DASKIN, M. S., DEAN, L. K. Location of Health Care Facilities. In SAINFORT, $F$

BRANDEAU, M., PIERSKALLA, W. Handbook of OR/MS in Health Care: A Handbook of Methods and Applications, Kluwer, 2004. 